\title{
Study on Optimal Damping Model of Very Large Offshore Semi-submersible Structure
}

\author{
Hyebin Lee, Yoon Hyeok Bae ${ }^{\oplus^{* *}}$, Dongeun Kim ${ }^{* * *}$, Sewan Park ${ }^{* * * *}$, \\ Kyong-Hwan Kim ${ }^{\text {*takt }}$ and Keyyong Hong \\ "Multidisciplinary Graduate School Program for Wind Energy, Jeju National University, Jeju, Korea \\ ** Deptartment of Ocean System Engineering, Jeju National University, Jeju, Korea \\ ${ }^{* * *}$ Faculty of Wind Energy Engineering Graduate School, Jeju National University, Jeju, Korea \\ ${ }^{* * * *}$ Korea Research Institute of Ships and Ocean Engineering, Daejeon, Korea \\ 초대형 반잠수식 해양 구조물의 최적 감쇠 모델에 대한 고찰 \\ 이혜빈 ${ }^{*}$ 배윤혁 $\mathbb{1}^{* *}$ - 김동은 \\ "제주대학교 풍력특성화협동과정 \\ "제주대학교 해양시스템공학과 \\ 체제주대학교 풍력공학부 \\ 산선박해양플랜트연구소
}

KEY WORDS: Linear damping 선형 감쇠, Quadratic damping 2차 감쇠, Nonlinear drag 비선형 항력, Semi-submersible 반잠수식, Coupled analysis 연성해석

\begin{abstract}
In order to analyze the response of the offshore structure numerically, the linear potential theory is generally applied for simplicity, and only the radiation damping is considered among various damping forces. Therefore, the results of a numerical simulation can be different from the motion of the structure in a real environment. To reduce the differences between the simulation results and experimental results, the viscous damping, which affects the motion of the structure, is also taken into account. The appropriate damping model is essential for the numerical simulation in order to obtain precise responses of the offshore structure. In this study, various damping models such as linear or quadratic damping and the nonlinear drag force from numerous slender bodies were used to simulate the free decay motion of the platform, and its characteristics were confirmed. The optimized damping model was found by comparing the simulation results to the experimental results. The hydrodynamic forces and wave exciting forces of the structure were obtained using WAMIT, and the free decay test was simulated using OrcaFlex. A free decay test of the scale model was performed by KRISO.
\end{abstract}

\section{1. 서 론}

해양 플랫폼과 같이 규모가 크고 복잡한 모델의 운동특성을 파악하기 위해서는 실물 크기 그대로의 설계 모델을 이용한 실 험을 진행하기 어렵기 때문에 수치해석을 수행하거나 축소한 모형을 이용하여 모형실험을 실시한다. 그러나 수치해석은 많 은 가정을 기반으로 하기 때문에 수치 해석의 결과가 실제 구 조물의 운동 특성을 정확히 구현한다고 보기는 어렵다. 특히 문 제의 단순화 및 계산 시간 단축을 위하여 선형 포텐셜 이론에
기반한 수치 해석을 수행할 경우에는 비압축성 및 비점성 유체, 비회전성 유동을 가정하고 다양한 비선형 효과들을 무시한다. 따라서 모형실험을 함께 수행하고, 수치해석의 결과와 비교하 여 수치해석에서 고려되지 못하는 부분을 보완할 수 있다. Chan et al.(1995)은 선박의 횡동요(Roll) 운동에 영향을 주는 감쇠력 계수를 추정하기 위한 수치적 방법을 제시하면서 선형과 2차의 감쇠력을 합한 모델, 그리고 선형과 3차의 감쇠력을 합한 모델 을 이용하여 검증을 수행하였다.

Takaki and Tasai(1973)는 빌지킬(Bilge keel)이 부착된 모형 선

Received 8 May 2017, revised 2 January 2018, accepted 25 January 2018

Corresponding author Yoon Hyeok Bae: +82-64-754-3485, yh.bae@jejunu.ac.kr ORCID: http://orcid.org/0000-0002-5198-4519 It is noted that this paper is revised edition based on proceedings of Annual Autumn Conference of KSOE 2016 in Busan.

This is an open access article distributed under the terms of the creative commons attribution non-commercial license (http://creativecommons.org/licenses/by-nc/3.0) which permits unrestricted non-commercial use, distribution, and reproduction in any medium, provided the original work is properly cited. 
박을 이용하여 강제 동요 실험을 수행하고 이를 수치적으로 모 사할 때, 3 차의 감쇠항을 더하면 더욱 근접한 횡동요 응답을 얻 을 수 있음을 확인하였다. Dalzell(1978)은 선박의 횡동요 응답 에 적합한 비선형 모델 중 해석적인 접근이 유리한 선형과 3 차 의 혼합된 감쇠 모델에 대하여 논의하였다. 이와 같이 그동안의 연구는 주로 선박의 횡동요 감쇠 현상에 초점이 맞추어 져 왔 으며, 비선형 감쇠항의 수치적 해법 제시의 관점에서 다양한 연 구가 이루어져 왔다.

본 연구에서는 하부가 다수의 폰툰(Pontoon) 및 수직, 수평 방 향 브레이스(Vertical or horizontal braces)로 이루어진 초대형 반 잠수식(Semi-submersible) 해양 플랫폼의 거동에 적합한 감쇠모 델을 선정하기 위하여 6자유도 자유감쇠 거동을 수치해석을 통 하여 시뮬레이션하고, 모형실험의 결과와 비교하여 선형 포텐 셜 이론에서 고려하지 못하는 적절한 감쇠모델을 찾아보았다. 이를 위하여 선형 및 2 차 감쇠와 같은 다양한 감쇠 모델을 적용 하여 실제 플랫폼의 운동 특성과 가장 유사한 결과를 보이는 감쇠 모델을 결정하였다. 또한 감쇠모델의 차이에서 기인하는 플랫폼의 운동 응답 특성을 파악하기 위하여 파도가 작용하는 해상 환경 하에서 3 시간 동안의 부유체-계류 시간영역 연성해 석을 수행하고, 플랫폼의 운동 응답을 통계분석 하였다.

\section{2. 해석 방법}

\section{1 해석 모델}

본 연구에서 해석에 사용한 반잠수식 플랫폼은 Fig. 1과 같이 선박해양플랜트연구소(KRISO, Korea Research Institute of Ships and Ocean Engineering)에서 제안한 부유식 해상 풍력-파력 복합 발전 플랫폼이다(Kim et al., 2015). 본 플랫폼이 설치될 대상 해 역은 제주도 서부의 차귀도 근방으로 수심은 $80 \mathrm{~m}$ 로 가정하였 다. 플랫폼의 4 개의 주 기둥(Column) 위에는 각각 $3 \mathrm{MW}$ 급 풍력 발전기가 1 기씩 설치되어 있으며, 플랫폼의 각 면마다 6 기의 파 력발전장치(Wave energy converter, WEC)가 설치되어 있다. 플 랫폼의 하부구조물은 반잠수식 구조물로써 Fig. 2와 같은 다수 의 세장체로 구성되어 있다.

파도의 영향 하에서 플랫폼의 동적 거동을 수치 시뮬레이션 하기 위하여 전체 플랫폼 중 수면 하부에 위치한 주 기둥, 폰툰, 수직 및 수평 방향 브레이스, 원통형의 파력발전장치가 Fig. 2 와

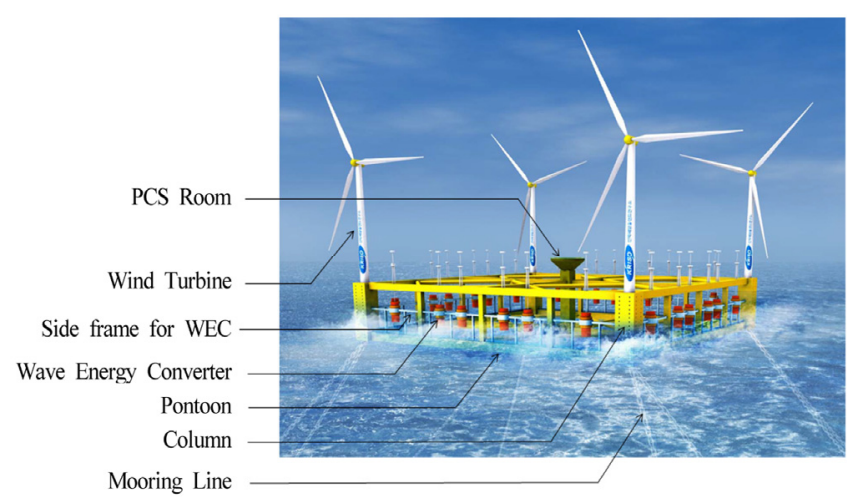

Fig. 1 Conceptual design of hybrid power generation platform

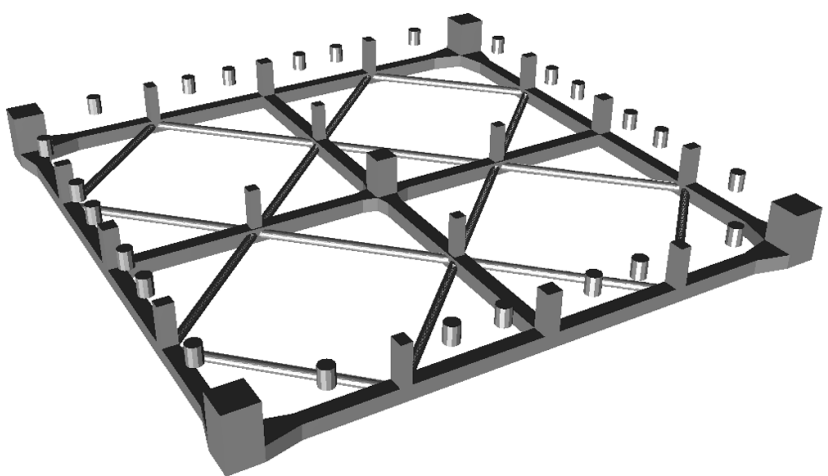

Fig. 2 Submerged geometry of hybrid power generation platform

Table 1 Specifications of hybrid power generation platform

\begin{tabular}{ccc}
\hline \hline Item & Unit & Value \\
\hline Overall platform displacement & {$[\mathrm{kgf}]$} & $27,266,000$ \\
Distance between two columns & {$[\mathrm{m}]$} & 150 \\
Draft & {$[\mathrm{m}]$} & 15 \\
Total WEC weight & {$[\mathrm{kgf}]$} & $1,777,000$ \\
Mooring load & {$[\mathrm{kgf}]$} & 343,000 \\
Center of gravity above keel & {$[\mathrm{m}]$} & 15.33 \\
\hline
\end{tabular}

같이 모델링 되었다. 구조물의 유체력 계산에 큰 영향을 미치지 않는 소형의 파력발전장치 지지 구조물(WEC guide frame) 등은 모델링하지 않았다. Table 1은 플랫폼의 제원을 나타낸다.

Fig. 3은 복합발전 플랫폼의 계류선의 배치를 보여준다. 그림 과 같이 플랫폼의 각 주 기둥마다 2 개씩, 총 8 개의 현수선으로

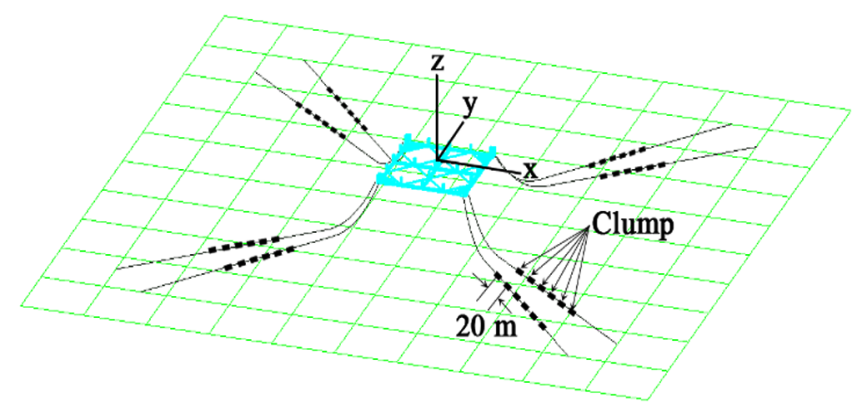

Fig. 3 Mooring line arrangements

Table 2 Specifications of mooring system

\begin{tabular}{ccc}
\hline \hline Item & Unit & Value \\
\hline Depth to fairleads below mean water level & {$[\mathrm{m}]$} & 13 \\
Unstretched mooring line length & {$[\mathrm{m}]$} & 500 \\
Chain diameter & {$[\mathrm{m}]$} & 0.147 \\
Wet mass density & {$[\mathrm{kg} / \mathrm{m}]$} & 374 \\
Total number of clump weights & {$[\mathrm{ea}]$} & 6 \\
Clump wet weight & {$[\mathrm{kgf}]$} & 11,000 \\
Spacing between clump weights & {$[\mathrm{m}]$} & 20 \\
Distance from fairlead to clump along the arc & {$[\mathrm{m}]$} & 130 \\
\hline
\end{tabular}


계류되어 있다. 각 계류선에는 6 개의 클럼프 웨이트(Clump weight)가 일정 간격을 두고 설치되어 있다. 계류선의 상세 제원 은 Table 2와 같다.

\section{2 감쇠력 해석}

플랫폼의 동유체력 계수 및 파 기진력, 2차 파 기진력은 포텐 셜 유동 기반의 방사/산란 문제 해석용 상용 프로그램인 WAMIT(Wave analysis at MIT)을 사용하여 주파수 영역에서 계 산하였다(Lee et al., 1991). WAMIT으로부터 계산된 계수를 이 용하여 플랫폼의 자유감쇠 시뮬레이션 및 시간 영역 운동 응답 해석을 수행하였고, 이는 Orcina사에서 개발한 부유체-계류 연 성해석 상용 프로그램인 OrcaFlex를 이용하였다(Orcina, 2015).

WAMIT은 선형 포텐셜 이론을 기반으로 한 주파수 영역의 유체력 해석 프로그램이기 때문에 구조물의 운동 응답 산출 시 점성의 영향은 무시되며, 일반적으로 방사감쇠력을 제외한 나 머지 감쇠력은 사용자의 필요에 따라 선형 감쇠의 형태로 추가 적으로 입력할 수 있다. 그러나 구조물의 운동 속도에 비례하는 선형 감쇠력은 실제 구조물의 감쇠 경향을 정밀하게 반영하지 못하는 단점이 있으며, 이러한 점에서 구조물의 운동을 시뮬레 이션 할 때에는 점성 또는 형상으로부터 기인하는 비선형 감쇠 력을 적용할 필요가 있다.

시간영역의 해석을 수행하면 다양한 비선형 효과를 포함시켜 플랫폼의 거동을 해석할 수 있는데 본 연구에서는 반잠수식 구 조물의 자유감쇠 거동을 OrcaFlex를 이용하여 시뮬레이션 하였 다. OrcaFlex는 WAMIT으로부터 계산된 동유체력 계수(부가질 량, 방사감쇠) 및 파 기진력을 이용하여 부유체-계류가 연성된 시간 영역 운동 해석을 수행한다. 이 때 시간 기억함수(Time memory function)로 포함되는 방사감쇠 효과와 더불어 구조물에 작용하는 추가적인 감쇠효과를 적용할 수 있는데, 구조물의 운 동 속도에 비례하는 선형 감쇠(Linear damping) 계수 혹은 속도 의 제곱에 비례하는 2차 감쇠(Quadratic damping) 계수를 이용하 는 방법이 있다. 선형 감쇠와 2 차 감쇠를 각각 단독으로 적용할 수 있으며, 필요에 따라서는 두 가지 감쇠력을 동시에 포함시킬 수도 있다. 선형 감쇠와 2차 감쇠는 각 운동 모드에 독립적으로 적용되므로, 부유체의 6자유도 운동 모드에 대하여 각각 독립적 으로 감쇠 계수를 선정하여야 한다.

선형 또는 2 차의 감쇠 모델 이외에도 세장체로 이루어진 개 별 부재(폰툰, 브레이스 등)에 대해 각각 모리슨 방정식의 항력 항을 이용하여 감쇠 모델을 구성할 수도 있다. 플랫폼을 구성하 는 개별 부재에 작용하는 항력을 모리슨 방정식의 항력 항을 이용하여 각각 산출 한 뒤, 이를 플랫폼에 작용하는 등가의 합 력 및 합모멘트로 변환하여, 플랫폼의 6자유도 운동 방정식에 외력으로 입력한다.

모리슨 방정식의 항력 항을 이용한 감쇠 모델을 적용하기 위 해서는 세장체의 형상에 따라 개별 세장 부재에 적절한 항력계 수를 적용해 주어야 한다. 이를 위하여 실험을 통하여 얻은 플 랫폼의 자유감쇠 경향을 잘 따르도록 개별 부재에 대해 적절한 항력계수를 선정할 필요가 있다. 이러한 경우에 플랫폼의 운동 해석 시 수많은 개별 부재에 대해 일일이 모리슨 방정식을 적 용하여 항력을 계산해야 하므로 수치 시뮬레이션 과정에 많은
시간이 소요되는 단점이 있다.

실제 모델과 비슷한 운동 결과를 얻기 위한 감쇠력을 결정하 기 위해서는 실험으로부터 계측된 자유감쇠의 결과와 자유감쇠 수치 시뮬레이션의 결과를 비교하며 선형 감쇠 계수, 2 차 감쇠 계수 혹은 항력을 계산하기 위한 개별 부재들의 항력계수를 찾 아야 한다(Robertson et al., 2014). 또한 세 가지 감쇠 모델 중 필 요에 따라서는 두 가지 이상의 모델을 조합하여 동시에 적용할 수도 있다.

\section{3. 감쇠 모델에 따른 자유감쇠 실험}

본 연구의 모델인 반잠수식 구조물의 운동 특성을 파악하기 위해서는 수치 해석을 진행하여야 한다. 그러나 수치 해석은 많 은 가정을 기반으로 물리적인 모델을 단순화 시켜 해석을 진행 하기 때문에 실제 구조물의 운동 특성과 정확히 일치하는 해석 결과를 기대하기는 어렵다. 일반적으로 구조물에 작용하는 여 러 감쇠력 중 방사 감쇠력을 제외한 감쇠력을 수치적으로 계산 하는 것은 어렵기 때문에 모형실험의 결과를 이용하여 적절한 감쇠 모델을 찾고 이를 수치 시률레이션에 적용하여야 한다.

본 구조물에 대한 자유감쇠 수리모형 시험이 설계 모델의 $1 / 50$ 비율로 축소된 모형을 이용하여 선박해양플랜트연구소에 서 수행되었으며, 이 결과를 수치 시뮬레이션의 결과와 비교하 여 Fig. 4에 실선으로 나타내었다. 감쇠 계수 및 항력 계수를 선 정하기 위하여 실험의 결과와 초기 변위를 동일하게 한 후, 첫 번째 운동 주기에서의 최댓값과 최솟값이 최대한 일치하도록 감쇠 계수 또는 항력 계수를 선정하였다. 그러나 비교적 구조물 의 운동 속도가 큰 초기의 데이터를 기준으로 감쇠 계수를 선 정하였기 때문에 속도가 작은 운동에서의 감쇠력을 추정하는 데는 어느 정도 한계가 있다.

각 감쇠 모델을 평가하는 데 있어서, 실험의 결과와 정량적으 로 값을 맞추기 위하여 정밀한 계수를 선정하기보다 각 감쇠 모델이 실험 결과의 경향을 얼마나 유사하게 구현할 수 있는지 를 살펴보았다. Fig. 4(a)는 전후동요의 결과, Fig. 4(b)는 상하동 요의 결과, Fig. 4(c)는 종동요의 결과를 비교한 그래프이다. 전 반적으로 선형 감쇠 계수를 적용하여 시뮬레이션 한 경우에는 전후동요 및 종동요의 감쇠가 급격히 발생하는 것을 확인할 수 있다. 반면 2차 감쇠 계수를 적용하거나 모리슨 항력을 이용한 감쇠를 적용하였을 때의 시뮬레이션 결과는 실험의 결과를 보 다 정확히 재현하는 경향을 보였다. 특히 2 차 감쇠 모델과 모리 슨 항력 모델 간은 사용된 계수의 차이로 인한 미세한 차이만 발생하는데 이는 자유감쇠 시뮬레이션이 유체입자의 운동이 없 는 정수 중에서 수행되었고, 정수 중에는 2 차 감쇠 모델과 모리 슨 항력 모델 간 등가의 감쇠계수가 적용되면 동일한 감쇠 거 동을 보이기 때문이다. 유체입자와 세장 부재 간의 상대속도의 제곱에 비례하는 모리슨 항력 모델은 파랑에 의한 유체입자의 운동이 존재할 경우에 2 차 감쇠 모델과 차이를 나타내게 되며, 이러한 이유로 자유감쇠 실험을 통하여 적절한 감쇠 모델을 선 정했다 하더라도, 그 감쇠 모델이 반드시 파랑이 존재하는 환경 하에서도 적합한 감쇠력을 나타내는 것은 아니라는 사실을 확 인할 수 있다. 


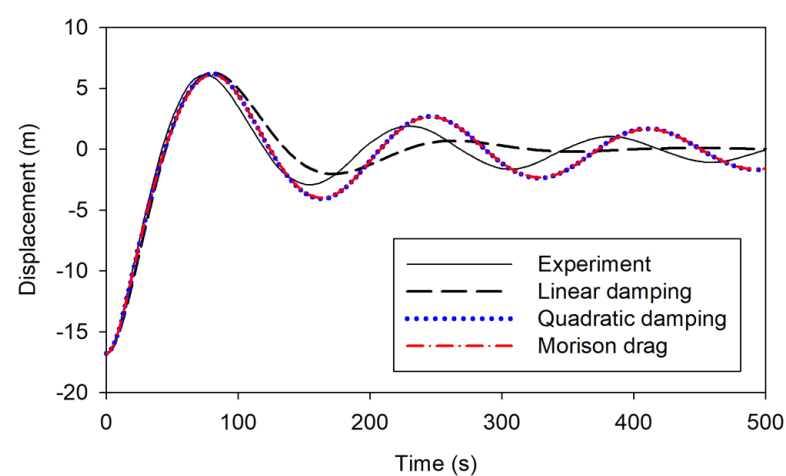

(a) Surge

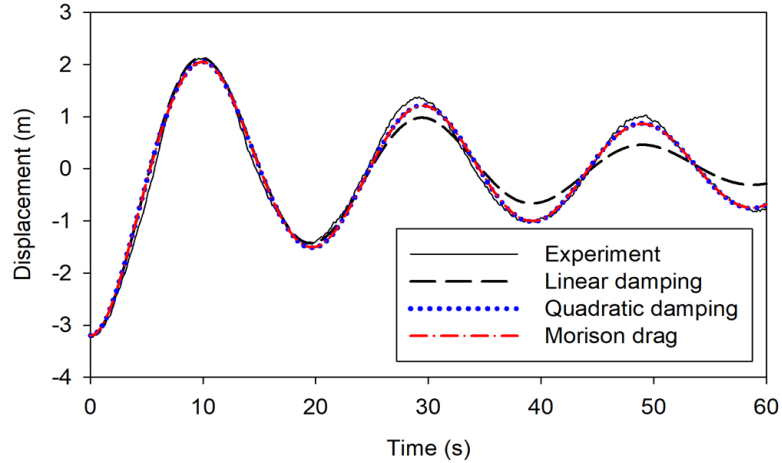

(b) Heave

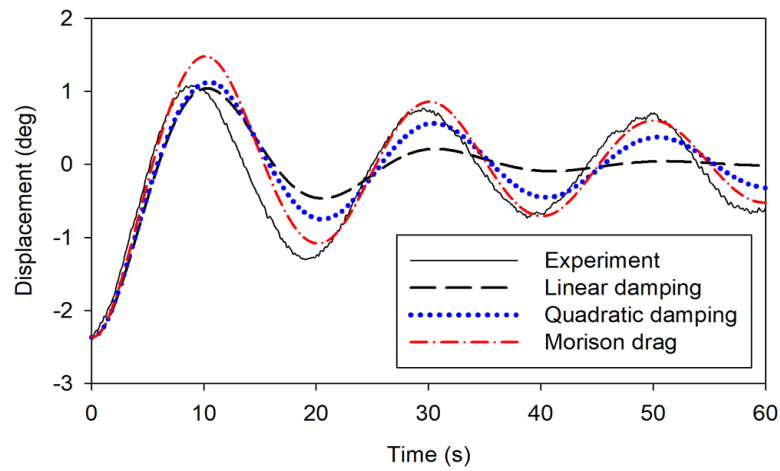

(c) Pitch

Fig. 4 Free decay simulation results(Linear damping, Quadratic damping, Morison drag) compared to free decay test results(Experiment)

\section{4. 불규칙 파랑 중 운동 응답}

앞에서 플랫폼의 자유감쇠실험 결과를 이용하여 플랫폼의 감 쇠 거동을 최대한 유사하게 모사할 수 있는 감쇠 계수 또는 항 력 계수를 각각의 감쇠 모델에 대하여 선정하였다. 그러나 이러 한 과정을 통하여 선정한 감쇠 모델은 정수 중의 플랫폼의 감 쇠 거동을 기준으로 선정 되었으므로 실제 해양 환경에 대한 플랫폼의 운동 특성을 파악하기 위해서는 불규칙 파랑 중 부유 체-계류 연성해석을 수행하여야 한다. 이 연구에서는 Table 3 와
같이 평시 조건(Normal condition), 극한 조건(Extreme condition), 생존 조건(Survival condition)의 3가지 경우에 대해 시뮬레이션 을 실시하였다. 설치 대상 해역의 해상환경을 토대로, 평시 조 건은 재현주기 1 년, 극한 조건은 재현주기 50년, 생존 조건은 재현주기 100 년의 해상환경에 해당하는 조건들을 적용하였으 며, 파랑만을 고려하고 바람은 따로 고려하지 않았다. 파랑스펙 트럼으로써 JONSWAP(Joint North Sea Wave Project) 스펙트럼을 이용하여 불규칙파를 생성하였다(Fig. 5). 입사파의 방향은 Fig. 6 과 같이 좌측에서 우측방향으로 작용하는 것으로 해석하였다.

Table 3 Environmental conditions

\begin{tabular}{cccccc}
\hline \hline & & Unit & Normal condition & Extreme condition & Survival condition \\
\hline \multirow{3}{*}{ Wave } & Significant wave height & {$[\mathrm{m}]$} & 5.93 & 11.28 & 12.88 \\
& Peak period & {$[\mathrm{s}]$} & 10.81 & 14.29 & 15.27 \\
& Peak shape parameter $(\gamma)$ & {$[-]$} & 2.2 & 2.2 & 2.2 \\
\hline
\end{tabular}

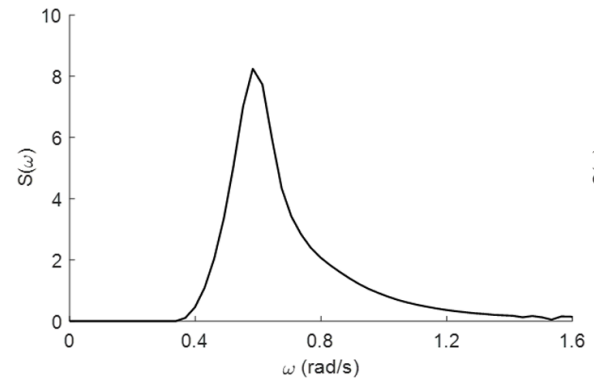

(a) Normal condition

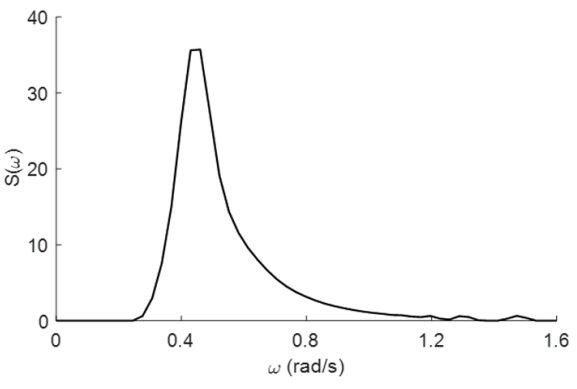

(b) Extreme condition

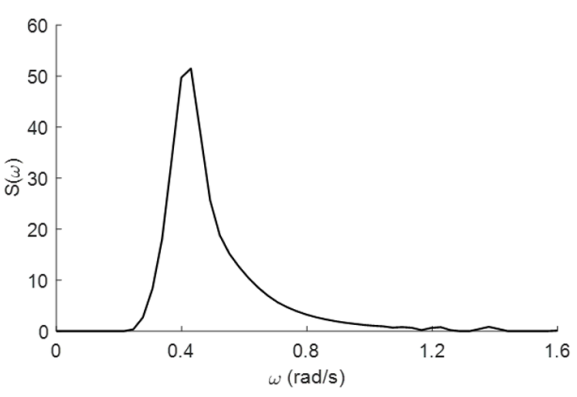

(c) Survival condition

Fig. 5 Wave spectra 


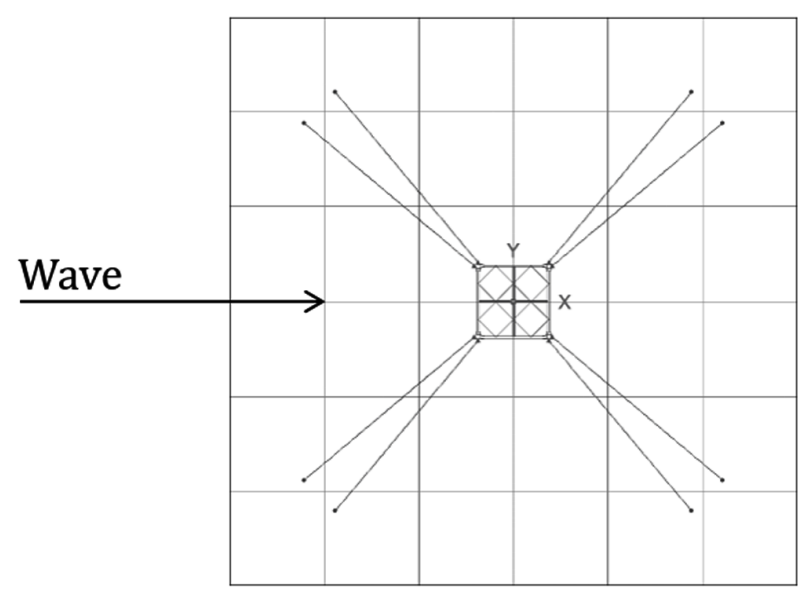

Fig. 6 Wave direction

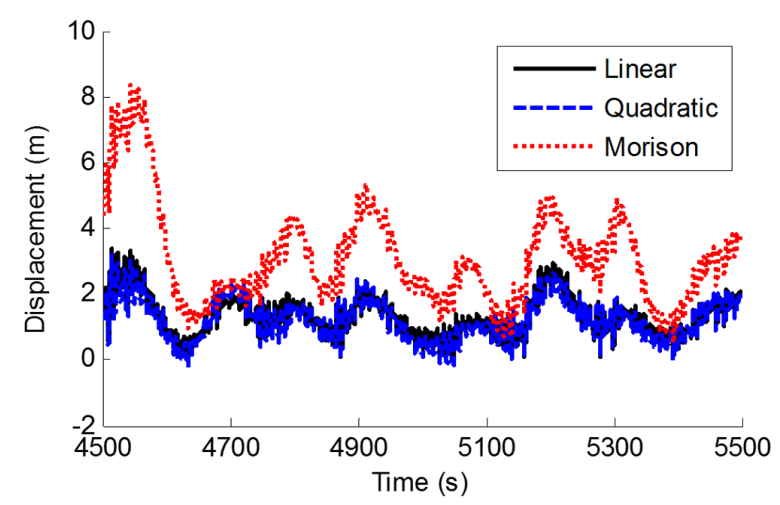

(a) Surge

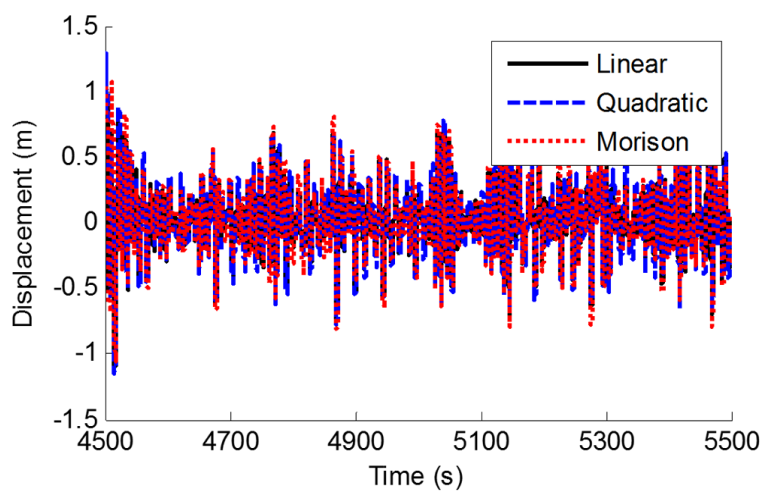

(b) Heave

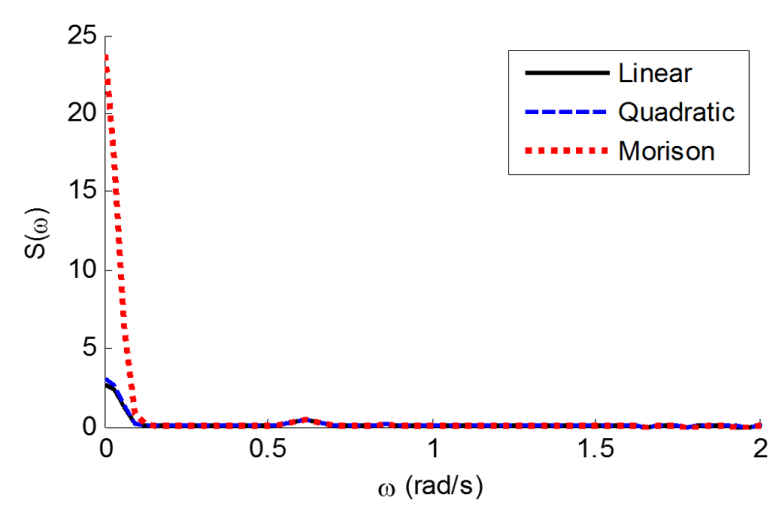

동안에는 점진적으로 외력을 증가시켰으며, 이후 플랫폼의 운 동 응답을 살펴보고자 10,800 초(3시간)의 시뮬레이션을 수행하 였다. Figs. 7-9는 각각 평시 조건, 극한 조건, 생존 조건에서의 플랫폼 전후동요(a), 상하동요(b), 종동요(c) 운동 변위 및 운동 스펙트럼을 보여준다. 운동 변위는 거동의 차이를 확인할 수 있 도록 일부 구간을 도시하였으며, 운동 스펙트럼은 초기 400초 동안의 결과를 제외하고 변위의 평균값을 0 으로 정규화 하여 구조물의 동적 성능을 확인하는데 활용하였다.

플랫폼의 전후동요의 경우, 세 가지 조건에서 동일하게 모리 슨 항력을 이용한 감쇠 모델을 적용하였을 때 유체 입자의 운 동과 부재들의 상대속도 차이에서 기인하는 표류력(Drift force) 이 발생하였음을 알 수 있다. 운동 스펙트럼에서도 모리슨 항력 을 이용한 감쇠 모델의 경우, 나머지 두 감쇠 모델의 결과에 비

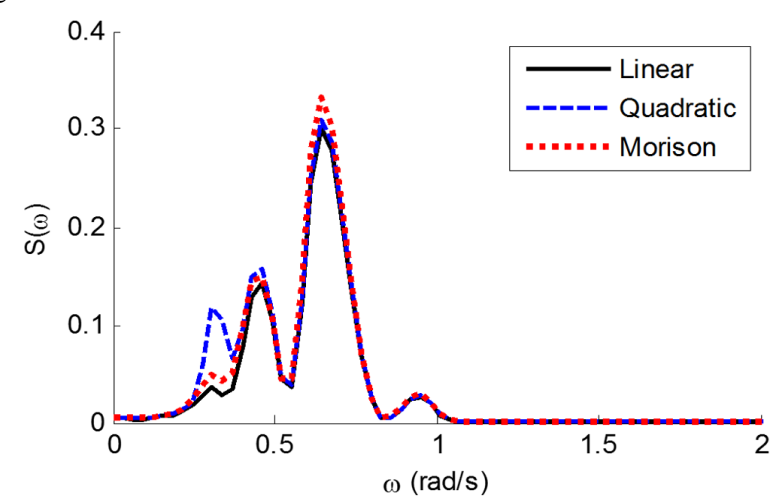

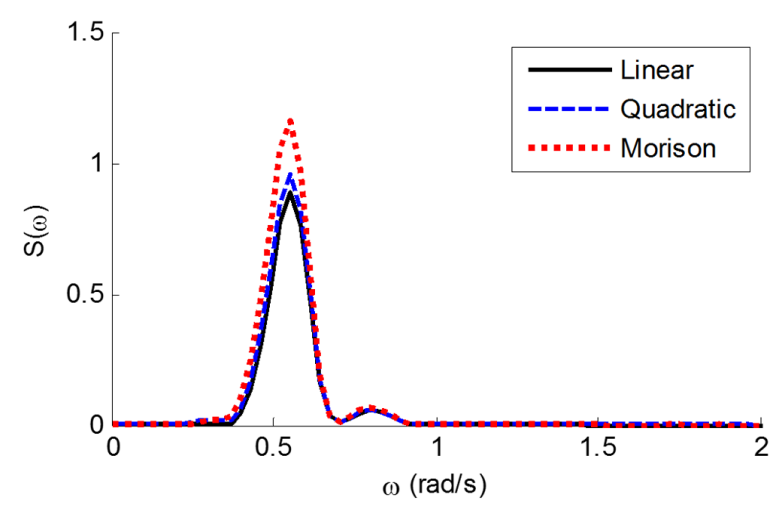

(c) Pitch

Fig. 7 Platform motion time histories(left) and motion spectra(right) under normal condition 

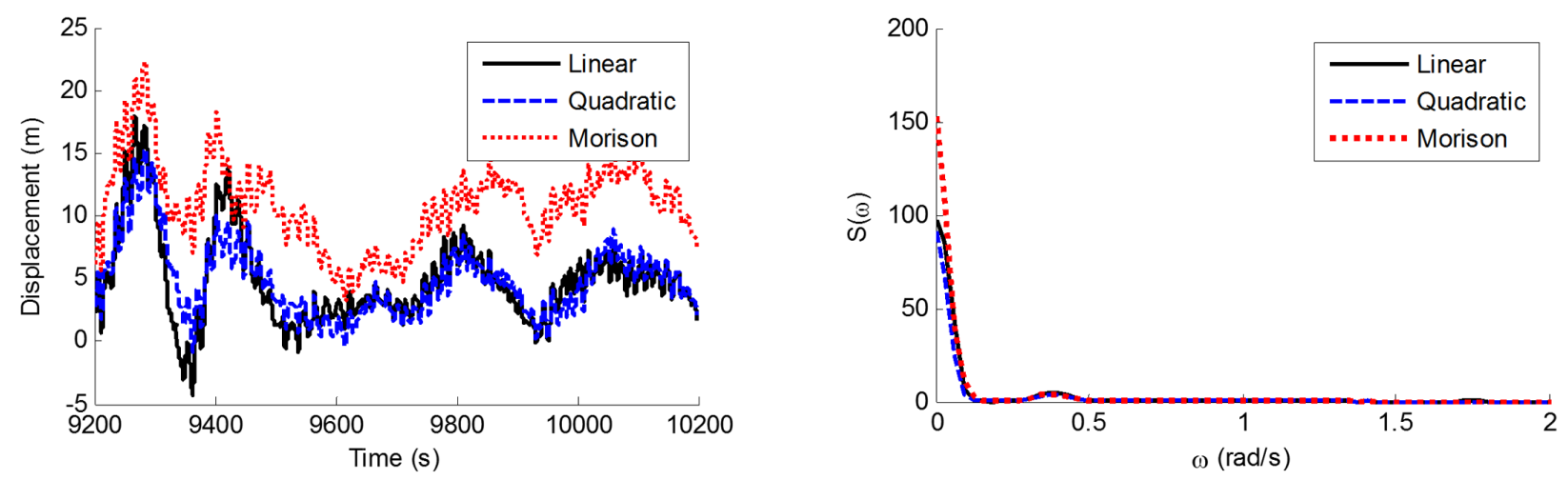

(a) Surge
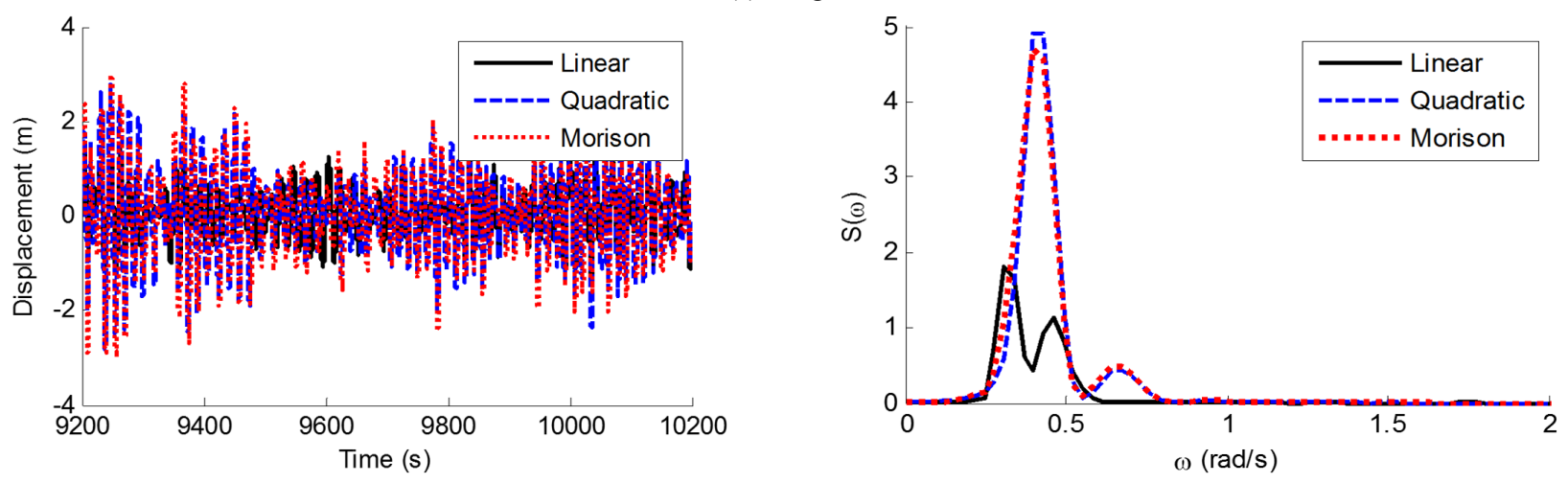

(b) Heave
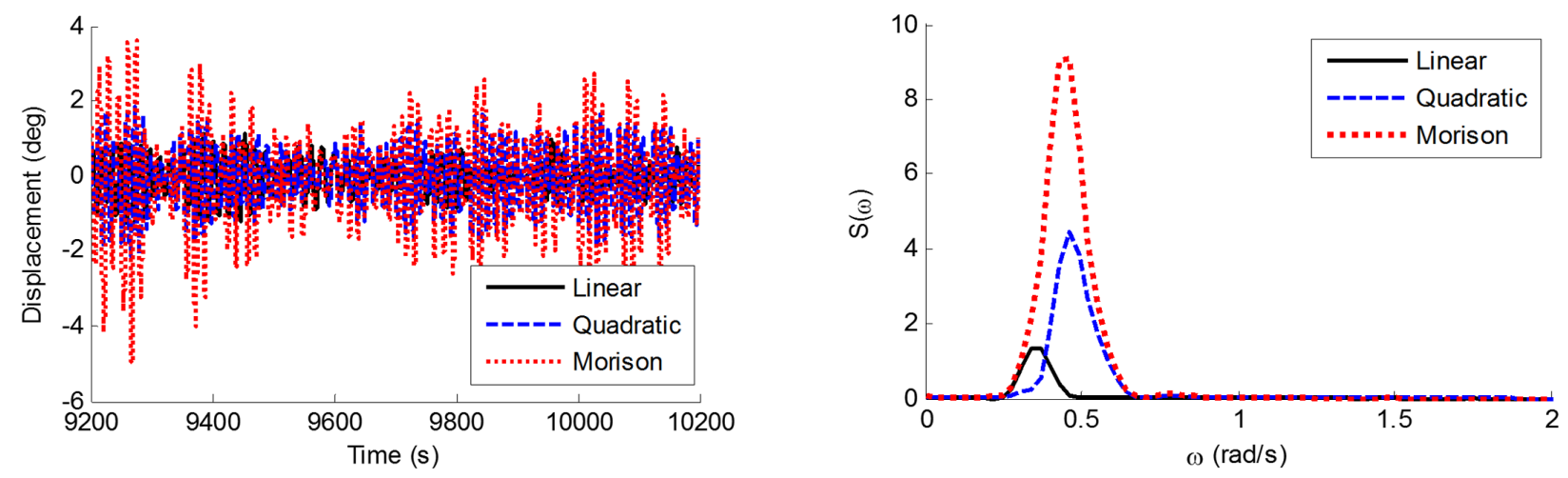

(c) Pitch

Fig. 8 Platform motion time histories(left) and motion spectra(right) under extreme condition

해 저주파수 영역에 에너지가 집중되거나(평시 조건, 극한 조

건) 혹은 에너지가 감소한 결과(생존 조건)를 보였다. 상하동요 운동 스펙트럼의 경우 세 감쇠 모델이 비슷한 수준의 에너지 분포를 보였으나, 종동요의 경우 Fig. 4(c)에서와 같이 감쇠 모 델별로 감쇠의 경향이 다소 차이 나므로 운동 응답 결과의 직 접적인 해석은 한계가 있다.

앞선 자유감쇠 시뮬레이션 결과에서는 플랫폼의 운동이 각각 독립적으로 발생하였기 때문에 2차 감쇠 모델을 적용하였을 때 에도 항력을 이용한 감쇠 모델을 적용하였을 때와 비슷한 수준 으로 실험의 결과와 근접한 결과를 얻을 수 있었으나, 실제 해 상환경을 대상으로 시뮬레이션을 할 경우에는 구조물의 복잡한 연성 거동으로 인한 항력 효과가 모두 고려되는 모리슨 항력 모델을 적용하여야 보다 실제와 근접한 해석 결과를 얻을 수 있을 것으로 판단되며 선형 또는 2 차 감쇠모델을 사용할 때는
유속과 구조물 운동의 상대속도 제곱까지는 아니더라도 최소한 유속의 제곱에 해당하는 모리슨 항력 영향을 고려하여 시뮬레 이션 하여야 근접한 결과를 얻을 수 있을 것이다.

Table 4는 평시 조건, 극한 조건, 생존 조건의 경우에 플랫폼 의 전후동요, 상하동요, 종동요 최대 가속도 값 및 선형 감쇠 모 델을 기준으로 계산한 각 감쇠 모델의 최대 가속도 값의 상대 적 비율을 보여준다. 플랫폼의 상단에는 풍력발전기가 탑재되 고, 풍력발전기의 너셀 부분은 플랫폼의 회전 운동 중심에서 상 당히 이격되어 있으므로 일반적으로 큰 가속도가 발생한다. 따 라서 본 시스템과 같이 풍력발전기를 포함한 전체적인 플랫폼 운동의 안정성을 확인하기 위해서는 플랫폼의 가속도 값을 정 확히 예측하는 것이 필요하다. Table 4 의 전후동요의 경우 선형 감쇠와 2 차 감쇠 모델의 차이는 $2 \%$ 이내로 큰 차이를 보이지 않 으나 모리슨 항력 모델의 경우 선형모델에 비하여 최대 가속도 

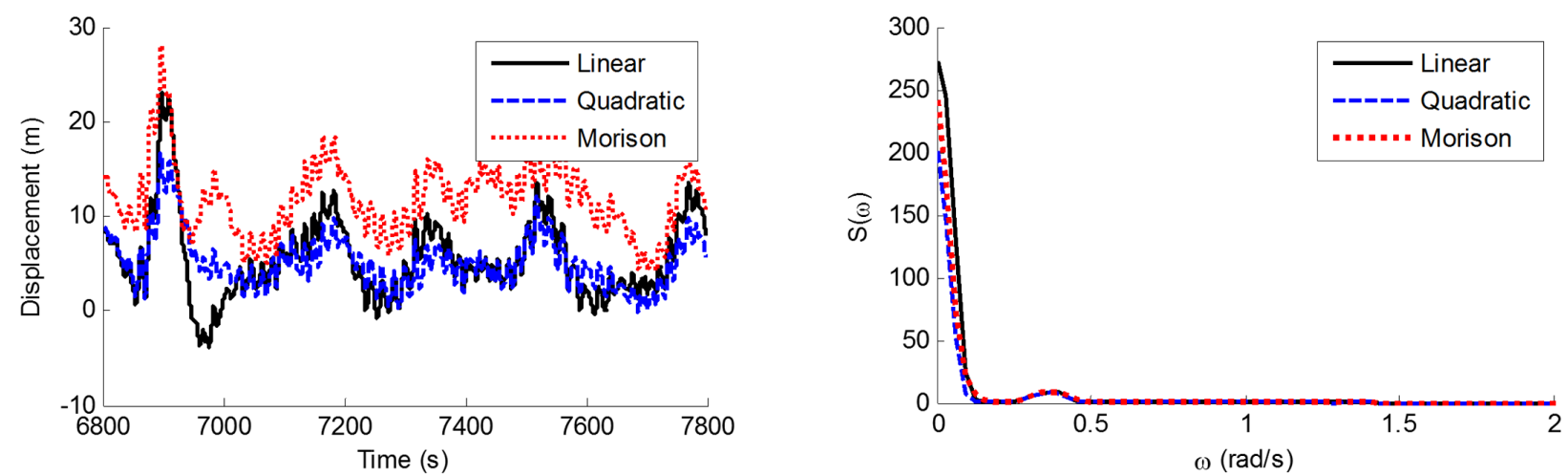

(a) Surge
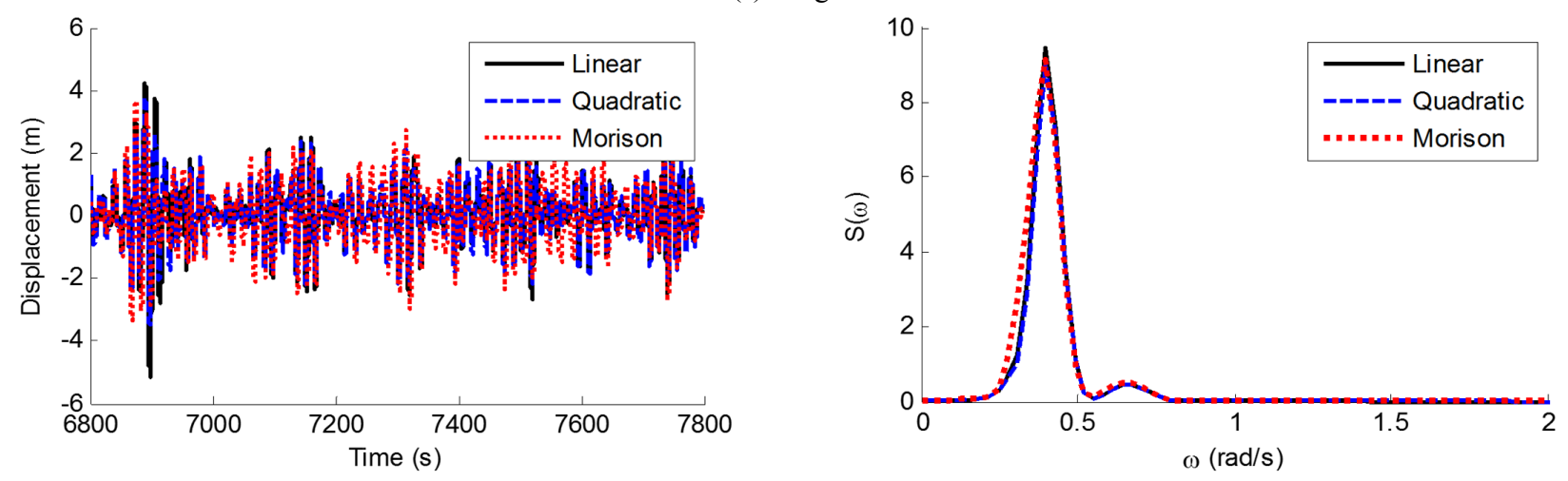

(b) Heave
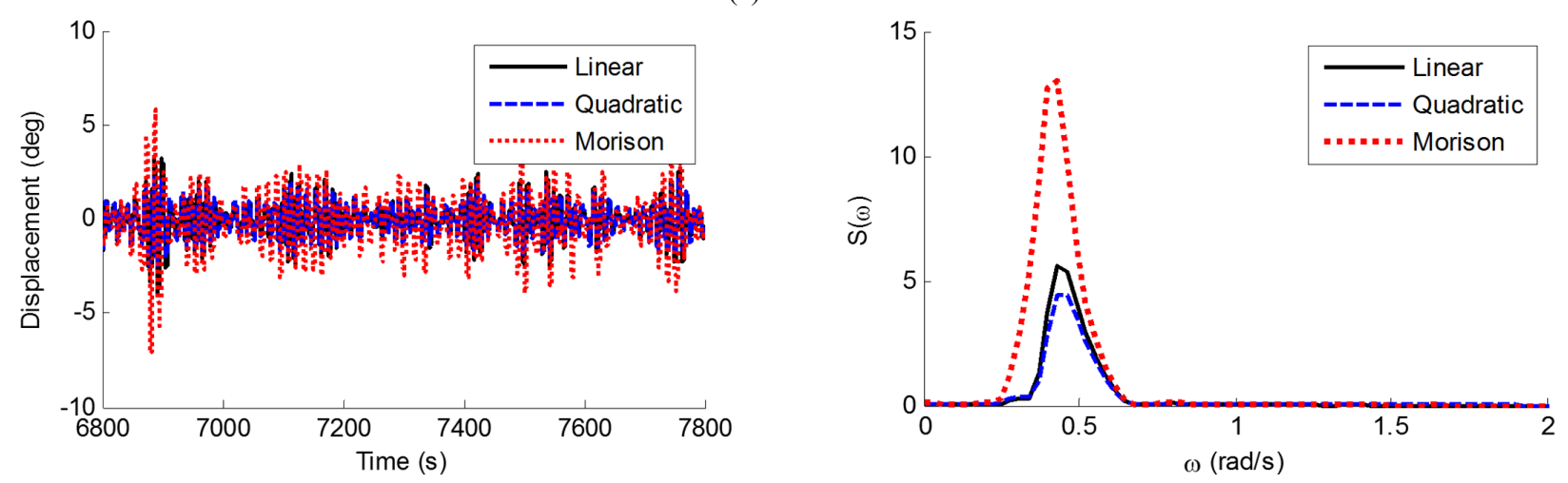

(c) Pitch

Fig. 9 Platform motion time histories(left) and motion spectra(right) under survival condition

Table 4 Maximum acceleration of platform

\begin{tabular}{ccccccccc}
\hline \hline & & \multicolumn{2}{c}{ Normal condition } & \multicolumn{2}{c}{ Extreme condition } & \multicolumn{2}{c}{ Survival condition } \\
\cline { 3 - 8 } & & Acc. $\left[\mathrm{m} / \mathrm{s}^{2}\right.$ or $\left.\mathrm{deg} / \mathrm{s}^{2}\right]$ & {$[\%]$} & Acc. $\left[\mathrm{m} / \mathrm{s}^{2}\right.$ or deg $\left./ \mathrm{s}^{2}\right]$ & {$[\%]$} & Acc. $\left[\mathrm{m} / \mathrm{s}^{2}\right.$ or deg $\left./ \mathrm{s}^{2}\right]$ & {$[\%]$} \\
\hline \multirow{3}{*}{ Surge } & 0.7175 & 100.00 & 0.8660 & 100.00 & 0.9765 & 100.00 \\
& Linear damping & 0.7167 & 99.89 & 0.8623 & 99.57 & 0.9590 & 98.21 \\
& Quadratic damping & Morison drag & 0.7603 & 105.97 & 0.9330 & 107.74 & 1.0201 & 104.47 \\
\hline \multirow{3}{*}{ Heave } & Linear damping & 0.4418 & 100.00 & 0.8986 & 100.00 & 0.9496 & 100.00 \\
& Quadratic damping & 0.4456 & 100.86 & 0.7880 & 87.69 & 0.7525 & 79.24 \\
& Morison drag & 0.4436 & 100.41 & 0.7952 & 88.49 & 0.8627 & 90.85 \\
\hline \multirow{3}{*}{ Pitch } & Linear damping & 0.4857 & 100.00 & 0.8079 & 100.00 & 0.9142 & 100.00 \\
& Quadratic damping & 0.4772 & 98.25 & 0.7363 & 91.14 & 0.7491 & 81.94 \\
& Morison drag & 0.5806 & 119.54 & 1.0617 & 131.41 & 1.2860 & 140.67 \\
\hline
\end{tabular}


가 환경 조건에 따라 약 4 8\% 정도 크게 나타난 것을 확인할 수 있다. 즉, 수치 시뮬레이션 수행 시 선택한 감쇠 모델에 따라 최대 가속도의 결과가 과소 또는 과대평가 될 가능성이 있다는 의미이다. 특히 2 차 감쇠 및 모리슨 항력 모델의 경우 Fig. 4(a) 에서 나타난 자유감쇠 경향은 서로 거의 일치하는 것으로 나타 났지만 실제 해상조건에서의 시뮬레이션 결과 운동 응답은 차 이가 남을 확인할 수 있다. 이는 유체입자의 속도를 고려한 상 대속도 제곱 항이 모리슨 항력 모델에는 포함되어 있기 때문으 로 해석 할 수 있다. Table 4의 상하동요의 경우 평시조건에서 의 최대 가속도는 감쇠 모델 간 큰 차이를 보이지 않으나 극한 조건 및 생존 조건에서는 2 차 감쇠 및 모리슨 항력 모델이 선형 감쇠 모델에 비하여 최대 가속도 값이 다소 작게 나타남을 확 인할 수 있다. 상하동요의 경우도 마찬가지로 Fig. 4(b)에 나타 난 것처럼 2 차 감쇠와 모리슨 항력 모델의 자유감쇠 경향은 거 의 일치하였지만 실제 해상조건의 시뮬레이션 결과 운동의 응 답은 다소 차이를 보임을 확인할 수 있다. Table 4의 종동요 최 대 가속도의 경우는 Fig. 4(c)의 자유감쇠 경향이 감쇠 모델별로 다소 차이를 보이기 때문에 직접적인 결과의 해석은 무리가 있 으나 궁극적으로는 적절한 감쇠모델을 적용한 운동 시뮬레이션 이 수행되어야만 플랫폼 상부의 다양한 구조물에 작용하는 가 속도에 대해 과대 또는 과소평가하게 될 위험을 줄일 수 있게 됨을 확인할 수 있다.

\section{5. 결 론}

해양구조물의 동적 거동에 대한 수치해석을 진행할 경우, 일 반적으로 문제를 단순화하기 위하여 선형 포텐셜 이론에 기반 한 부유체-계류 연성 해석을 수행하게 된다. 그러나 선형 포텐 셜이론은 방사감쇠력을 제외하고 해양구조물에 미치는 추가적 인 다양한 감쇠력을 고려하지 않기 때문에 수치 해석으로는 실 제 구조물의 운동과 유사한 결과를 구현하기 어렵다. 따라서 구 조물에 작용하는 다양한 감쇠력을 추가로 적용해 주어야 보다 정확한 운동 해석 결과를 얻을 수 있다.

본 연구에서는 감쇠 모델 중 선형 감쇠력, 2 차 감쇠력 혹은 모리슨 방정식의 항력 항을 이용하여 구조물의 운동에 미치는 감쇠력을 실제 실험 결과와 비슷한 수준으로 맞추고자 하였다. 각 감쇠 모델에 적정한 값을 찾기 위하여 설계 모델의 모형에 대해 실시한 자유감쇠 실험의 결과와 비교하여 가장 근접한 운 동 결과를 보이는 감쇠 계수 또는 항력 계수를 선정하였다.

자유감쇠실험의 결과와 감쇠 모델을 적용하여 실시한 자유감 쇠 시뮬레이션 결과를 관찰하면, 2 차 감쇠 모델 및 항력을 이용 한 감쇠 모델을 적용하였을 때 선형 감쇠 모델에 비하여 실험 의 결과와 근접한 수준의 결과를 얻을 수 있음을 확인할 수 있 었다. 실제 해상 환경 하에서의 각 감쇠 모델에 따른 운동의 차 이를 확인하기 위하여 평시 조건, 극한 조건, 생존 조건에 대해 시간영역 운동 시뮬레이션을 실시하였으며 그 결과 2 차 감쇠 모델과 모리슨 항력 모델은 자유감쇠 시뮬레이션에서는 거의
일치하는 운동 응답을 보였음에도 실제 해상 환경의 시뮬레이 션에서는 두 응답이 차이가 남을 확인하였다. 이는 모리슨 항력 모델이 구조물의 부재를 관통하는 유체입자 속도와 그 부재의 운동 속도간의 상대속도를 고려하기 때문으로 해석할 수 있다.

이와 같은 결과를 통하여 정밀한 해양 구조물의 거동 예측을 위해서는 그 구조물의 감쇠 경향을 잘 나타내는 적절한 감쇠 모델을 적용해야 함을 알 수 있으며 적절한 감쇠 모델을 이용 하여 예측된 정확한 구조물의 거동은 구조 신뢰성 검증 및 계 류선의 최적 설계 등에 활용될 수 있다.

\section{후 기}

본 연구는 2016년도 산업통상자원부의 재원으로 한국에너지기 술평가원(KETEP)의 에너지인력양성사업 「육해상 풍력터빈 신뢰 성 및 발전량 향상을 위한 O\&M 기술 고급트랙」으로 지원받아 수행한 인력양성 성과입니다(No. 20164030201230). 또한 해양수 산부의 국가 R\&D 사업인 ' $10 \mathrm{MW}$ 급 부유식 파력-해상풍력 연계 형 발전시스템 설계기술 개발’ 과제(PMS3170)에 의해 수행되었으 며, 연구비 지원에 감사드립니다.

\section{References}

Chan, H.S.Y., Xu, Z., Huang, W.L., 1995. Estimation of Nonlinear Damping Coefficients from Large-amplitude Ship Rolling Motions. Applied Ocean Research, 17(4), 217-224.

Dalzell, J.F., 1978. A Note on the Form of Ship Roll Damping. Journal of Ship Research, 22(3), 178-185.

Kim, K.H., Lee, K.S., Sohn, J.M., Park, S.W., Choi, J.S., Hong, K., 2015. Conceptual Design of 10MW Class Floating Waveoffshore Wind Hybrid Power Generation System. Proceedings of 25th International Offshore and Polar Engineering Conference, Kona USA, 1, 737-743.

Lee, C.H., Newman, J.N., Kim, M.H., Yue, D.K.P., 1991. The Computation of Second-order Wave Loads by WAMIT. Proceeding of 7th International Conference on Offshore Mechanics and Artic Engineering, Stavanger Norway, 113-123.

Orcina Ltd., 2015. OrcaFlex Manual version 10. Orcina Ltd., Daltongate, Ulverston, Cumbria UK, [Online] Available at: $<$ http://www.orcina.com> [Accessed April 2017].

Robertson, A., Jonkman, J., Masciola, M., Song, H., Goupee, A., Coulling, A., Luan, C., 2014. Definition of the Semisubmersible Floating System for Phase II of OC4. NREL Technical Report, NREL/TP-5000-60601.

Takaki, M., Tasai, F., 1973. On the Hydrodynamics Derivative Coefficients of the Equations of Lateral Motions of Ships. Transactions of the West-Japan Society of Naval Architects, 46. 